\title{
Generation of mice derived from embryonic stem cells using blastocysts of different developmental ages
}

\author{
Hiroshi Ohta, Yuko Sakaide and Teruhiko Wakayama \\ Laboratory for Genomic Reprogramming, Center for Developmental Biology, RIKEN, 2-2-3 Minatojima- \\ Minamimachi, Chuo-ku, Kobe 650-0047, Japan \\ Correspondence should be addressed to H Ohta; Email: ohta@cdb.riken.jp
}

\begin{abstract}
We previously showed that increasing the cell number of host tetraploid (4n) embryos by aggregating multiple $4 \mathrm{n}$ embryos at two to fourcell stages can improve the birthrate of mice from embryonic stem cells (ES mice). In the present study, we assessed whether in vitro aged blastocysts (e.g., E4.5 or E5.5), where their cell number also increased with development, can be used as hosts for generating ES mice. As expected, the cell number of in vitro aged $4 \mathrm{n}$ blastocysts increased with development, i.e., $26.5 \pm 2.4,49.6 \pm 8.4$, and $84.9 \pm 20.9$ cells for E3.5, E4.5, and E5.5 respectively. Three independent ES cell lines were injected into $4 \mathrm{n}$ aged blastocysts, and their developmental ability was compared with that of E3.5 $4 \mathrm{n}$ blastocysts commonly used for this procedure. We found that the birthrate of ES mice derived from E4.5 blastocysts were comparable with those of mice generated from E3.5 blastocysts. On the other hand, the birthrates decreased when E5.5 blastocysts were used. These results suggest that not only the cell number but also developmental age is important for producing ES mice. We also discuss a comparison of the present findings with those of our previous study, where ES mice were generated using an aggregation method employing the same ES cell lines.
\end{abstract}

Reproduction (2008) 136 581-587

\section{Introduction}

The production of mouse chimeras is a common step in the establishment of genetically modified mouse strains. Chimeric mice are usually produced by injecting or aggregating embryonic stem (ES) cells into diploid (2n) host preimplantation embryos (Nagy et al. 2003) composed of modified donor cells and cells derived from the host embryo. The contribution of donor ES cells to the germ line of chimeric mice allows the generation of mouse strains carrying the haplotype of the ES cells. In general, the production of a mutant strain via this procedure is a time-intensive task, taking more than 12 months before adult mutants can be analyzed. To accelerate the production of mutant mouse lines, a tetraploid (4n) embryo complementation assay has also been established (Nagy et al. 1990, 1993). Since $4 \mathrm{n}$ embryos are not capable of completing normal development independently (Kaufman \& Webb 1990, Eakin \& Behringer 2003), ES cells aggregated with $4 \mathrm{n}$ embryos develop into conceptuses in which embryonic lineages are derived entirely from ES cells and extra-embryonic lineages arise largely from the 4n component (Nagy et al. 1990, 1993). Mice derived from ES cells (ES mice) show normal phenotypes, growth, and fertility (Nagy et al. 1993), indicating that ES mice can be used as founders for establishing mouse lines. Because all germ cells in ES mice are derived from ES cells, germ line transmission of ES cells is easier in ES mice than in $2 n$ chimeric mice. Thus, producing $\mathrm{ES} \leftrightarrow 4 \mathrm{n}$ embryos would be effective for analyzing gene function in vivo.

Although the methodology for producing ES mice derived from ES cell lines was described more than a decade ago (Nagy et al. 1990, 1993), its application remains limited due to the extremely low frequency at which viable ES mice are recovered (Nagy et al. 1990, 1993). We previously used a technique where increasing the cell number of host $4 \mathrm{n}$ embryos enhanced the production of ES mice (Ohta et al. 2008). The important advantage gained from the improvement of this technique, which was achieved by increasing the cell number of host $4 \mathrm{n}$ embryos, was that it could be applied to any ES cell lines such as those commonly used for gene targeting. However, additional host $4 \mathrm{n}$ embryos are required in order to reconstruct $\mathrm{ES} \leftrightarrow 4 \mathrm{n}$ chimeric embryos. If this required number can be reduced, the production of ES mice will become easier and more efficient than our previous procedure.

In the present study, we increased the cell number of host $4 \mathrm{n}$ embryos by prolonged in vitro culturing, and assessed the functional ability of these in vitro aged blastocysts to generate ES mice. 

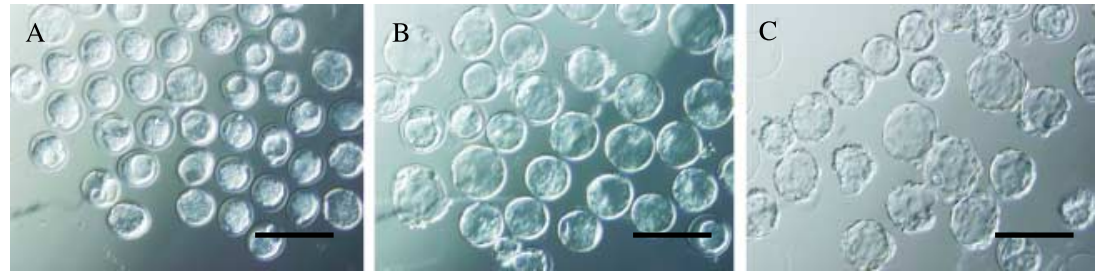

Figure 1 Blastocoel formation of $4 \mathrm{n}$ preimplantation embryos of different developmental ages. (A-C) Light micrographs of $4 \mathrm{n}$ preimplantation embryos of different ages; (A) E3.5 embryos, (B) E4.5 embryos, (C) E5.5 embryos.

Scale bars $=200 \mu \mathrm{m}$.

\section{Results}

\section{Characterization of in vitro aged blastocysts}

We initially characterized $4 \mathrm{n}$ blastocysts at different developmental ages (E3.5, E4.5, and E5.5) before the in vitro aged blastocysts were used to produce ES mice. We examined the blastocoel formation of $4 \mathrm{n}$ aged blastocysts, and the trophectoderm (TE) and inner cell mass (ICM) cell numbers of $4 \mathrm{n}$ aged blastocysts. At E3.5, approximately half of the $4 \mathrm{n}$ embryos were formed blastocoel (Fig. 1A: Table 1); therefore, we used and analyzed blastocoel forming E3.5 embryos in the present study. On the other hand, almost all $4 \mathrm{n}$ embryos at E4.5 and E5.5 formed a blastocoel (Fig. 1B and C; Table 1).

We then assessed the cell number of in vitro aged $4 \mathrm{n}$ blastocysts to examine whether this number actually increased. The total cell numbers of E3.5, E4.5, and E5.5 $4 \mathrm{n}$ blastocysts were $26.5 \pm 2.4,49.6 \pm 8.4$, and $84.9 \pm 20.9$ respectively (Fig. 2; Table 2), showing an increase with development as expected. The TE cell number of E5.5 4n blastocysts showed an 3.7- and1.8-fold increase from those of E3.5 and E4.5 4n blastocysts respectively. On the other hand, no obvious difference was found in ICM cell number among the blastocysts (Table 2). Consistent with the results of a previous study (Liu etal. 2004), the ICM cells in E4.5 (not shown) and E5.5 (Fig. 2D-D") 4n blastocysts were predominately stained by the POU5F1 antibody, suggesting that the specification and allocation of TE and ICM occurred normally in these $4 \mathrm{n}$ aged embryos. Thus, we succeeded in increasing the cell number of host $4 \mathrm{n}$ blastocysts with normal TE and ICM allocations by prolonged culturing.

\section{Generation of ES mice using in vitro aged $4 n$ blastocysts}

To assess whether in vitro aged $4 \mathrm{n}$ blastocysts can produce ES mice, ES cells were injected into E3.5, E4.5, and E5.5 $4 \mathrm{n}$ blastocysts. A total of $\sim 100$ reconstructed embryos were transferred for each donor and host developmental age. We generated ES mice from all three ES cell lines at $\sim 2-7 \%$ using E3.5 host blastocysts (Table 3). The birthrate of ES mice derived from E4.5 blastocysts was similar to that of ES mice generated from E3.5 blastocysts, but was lower when E5.5 blastocysts were used (Table 3). We also confirmed the high contribution of ES cells in the progeny derived from 129B6F1G1 $\leftrightarrow \mathrm{E} 4.5$ blastocysts by the presence of green fluorescent protein (GFP)-positive cells (Fig. 3), indicating that ES mice can be generated from E4.5 host embryos. In addition, the frequency of abnormal pups was similar in both E4.5 and E3.5 blastocysts (Table 4). Thus, although the E3.5 and E4.5 4n blastocysts can generate ES mice, the production of such mice was not improved using E5.5 4n blastocysts even if its cell number was relatively higher than that of the other blastocysts. These results indicate that not only the cell number but also the developmental age of host $4 \mathrm{n}$ embryos is important for generating ES mice.

\section{Implantation ability of in vitro aged $4 n$ blastocysts and tracing of ES cells injected into host $4 n$ blastocysts}

Although our results indicate that the E5.5 4n blastocysts are not an effective means of producing ES mice, the underlying mechanisms are largely unknown. To address this issue, we assessed the implantation abilities of in vitro aged $4 \mathrm{n}$ blastocysts. Thus, $4 \mathrm{n}$ blastocysts were transferred into pseudopregnant females without the injection of ES cells. Since $4 \mathrm{n}$ embryos die during early embryonic development (Eakin et al. 2005), the analysis was performed at E7.5. The implantation abilities of the $4 \mathrm{n}$ embryos were estimated as the numbers of decidua and embryos recovered. As shown in Table 5, the implantation and developmental abilities of the E5.5 4n blastocysts were not lower than those of the other blastocysts examined. This suggests that the low birthrate observed for ES mice from E5.5 $4 \mathrm{n}$ embryos is not related to the implantation and developmental abilities of the host $4 \mathrm{n}$ embryos.

Another possible reason for the low birthrate of ES mice from E5.5 4n blastocysts is that the ES cells injected into the E5.5 4n blastocysts do not contribute to the ICM. To assess the homing efficiency of ES cells into the ICM, ES cells that expressed GFP (129B6F1G1) were injected into E3.5, E4.5, and E5.5 4n blastocysts and these cells were analyzed $24 \mathrm{~h}$ later. Host ICM cells were identified based on morphology or immunofluorescence for POU5F1, which was visualized as red fluorescence.

Table 1 Blastocoel formation of preimplantation $4 \mathrm{n}$ embryos of different developmental ages.

\begin{tabular}{lcc}
\hline E3.5 & E4.5 & E5.5 \\
\hline $39 / 72(54.2 \%)$ & $72 / 72(100 \%)$ & $68 / 72(94.4 \%)^{\mathrm{a}}$
\end{tabular}

The numbers of blastocysts that form blastocoels are shown. ${ }^{\mathrm{a}}$ Four embryos degenerated at E5.5. 
PI
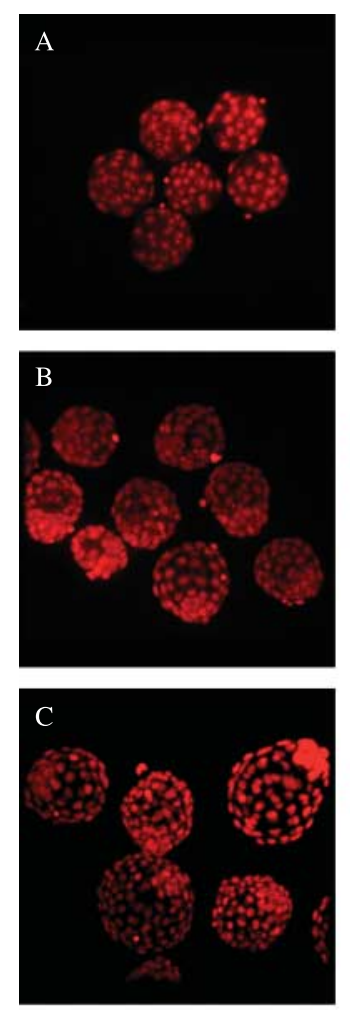

PI

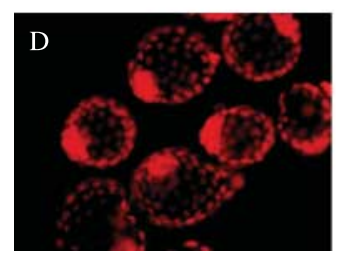

$\mathrm{CDX} 2$
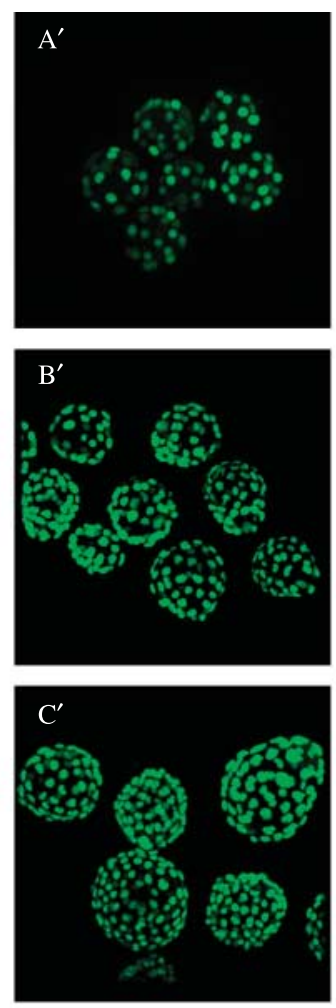

POU5F1

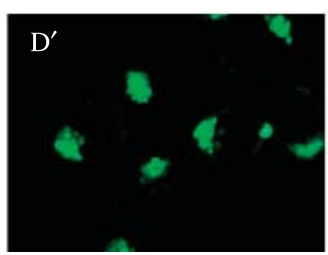

Merge
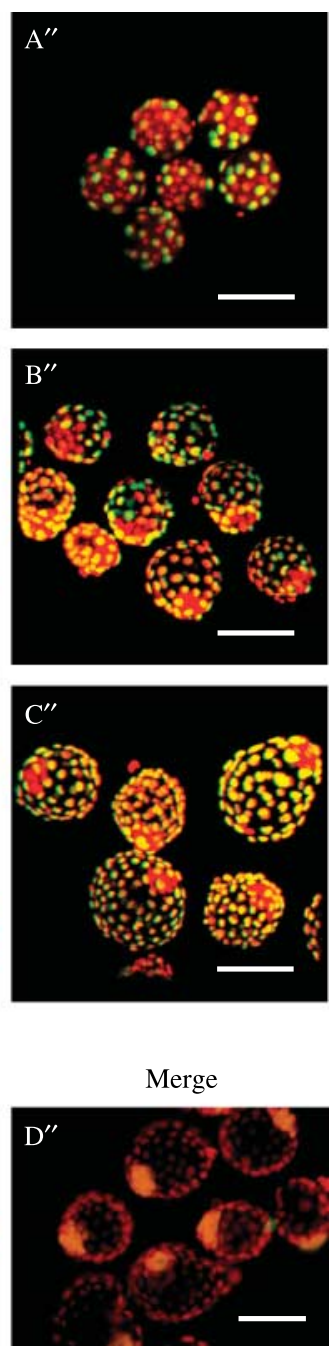

Figure 2 Immunostaining of $4 \mathrm{n}$ blastocysts of different developmental ages with CDX2 or POU5F1 antibodies. The $4 \mathrm{n}$ blastocysts of different developmental ages were stained with propidium iodide $(\mathrm{PI} ; \mathrm{A}-\mathrm{D})$ and $\mathrm{CDX} 2\left(\mathrm{~A}^{\prime}-\mathrm{C}^{\prime}\right)$. Merged photographs are shown in $\left(A^{\prime \prime}-D^{\prime \prime}\right)$; (A-A $\mathrm{A}^{\prime \prime}$ ) E3.5 blastocysts; (B-B") E4.5 blastocysts; and $\left(\mathrm{C}-\mathrm{C}^{\prime \prime}\right) \mathrm{E} 5.5$ blastocysts. In D-D", E5.5 blastocysts were stained with PI (D) or POU5F1 antibody $\left(\mathrm{D}^{\prime}\right)$. (A-C') Stacked serial images of the blastocysts obtained by confocal microscopy are shown. (D-D") Images were taken under fluorescence microscopy. Scale bars $=100 \mu \mathrm{m}$.
We found that ES cells injected into E3.5 4n or E4.5 4n blastocysts contributed significantly to the host ICM (Table 6 and Fig. 4A-A ${ }^{\prime \prime \prime}$ ). By contrast, there was a relative weak contribution of ES cells to the ICM in the case of E5.5 4n blastocysts (Table 6, Fig. 4B-B'"I). These results suggest that the low birthrate of ES mice from E5.5 $4 \mathrm{n}$ blastocysts is due to inefficient $\mathrm{ES}$ cell contribution to the host $4 \mathrm{nICM}$.

Finally, we examined the differences between E4.5 and E5.5 $4 \mathrm{n}$ blastocysts. It is known that the ICM differentiates into the primitive endoderm (PrE, the future yolk sack) and epiblast (future embryo), at around E4.5 in the case of a normal embryo (Kunath et al. 2005). Therefore, we examined by immunofluorescence the expression of GATA4, which is one of the markers for $\mathrm{PrE}$, in E4.5 4n and E5.5 4n blastocysts. As shown in Fig. 4, 6\% (3/50) of the E4.5 4n blastocysts formed PrE, whereas $\sim 60 \%(34 / 56)$ of the E5.5 $4 \mathrm{n}$ blastocysts formed PrE. These results indicate that the ICM of E5.5 $4 \mathrm{n}$ blastocysts has already differentiated into PrE and epiblast, and this may inhibit ES cell contribution to the ICM of E5.5 4n blastocysts.

Table 2 Cell number of $4 \mathrm{n}$ blastocysts of different developmental ages.

\begin{tabular}{lccc}
\hline Type of embryo & Total cell number (PI staining) & TE cell number (CDX2 staining) & ICM cell number (total-TE) \\
\hline E3.5 & $26.5 \pm 2.4^{\mathrm{a}}$ & $20.3 \pm 2.1^{\mathrm{c}}$ & $6.2 \pm 2.1$ \\
E4.5 & $49.6 \pm 8.4^{\mathrm{a}^{\prime}, \mathrm{b}}$ & $42.6 \pm 7.8^{\mathrm{c}^{\prime}, \mathrm{d}}$ & $7.4 \pm 6.7$ \\
E5.5 & $84.9 \pm 20.9^{\mathrm{a}^{\prime}, \mathrm{b}^{\prime}}$ & $75.8 \pm 16.3^{\mathrm{c}^{\prime}, \mathrm{d}^{\prime}}$ & $9.6 \pm 7.8$ \\
\hline
\end{tabular}

$\mathrm{a,a^{ \prime } ; b , b ^ { \prime } ; c , c ^ { \prime } ; d , d ^ { \prime }} P<0.05$ (Student's $t$-test). 
Table 3 Birthrate of embryonic stem cell (ES) mice using 4n blastocysts of different developmental ages.

\begin{tabular}{|c|c|c|c|c|c|}
\hline Donor ES & $\begin{array}{c}\text { Culture period of } 4 n \\
\text { blastocysts }\end{array}$ & $\begin{array}{c}\text { Number of } \\
\text { transferred embryos }(\mathrm{ET})\end{array}$ & Number of pups (\%) & Imp* & $\begin{array}{c}\text { Implantation rate } \\
(\text { pup }+i m p / E T)\end{array}$ \\
\hline \multirow[t]{3}{*}{ E14 } & E3.5 & 105 & $4(3.8)$ & 25 & $27.6 \%$ \\
\hline & E4.5 & 105 & $4(3.8)$ & 48 & $49.5 \%$ \\
\hline & E5.5 & 106 & 0 & 0 & 0 \\
\hline \multirow[t]{3}{*}{ 129B6F1G1 } & E3.5 & 105 & $2(1.9)$ & 19 & $20 \%$ \\
\hline & E4.5 & 124 & $2(1.6)$ & 43 & $36.2 \%$ \\
\hline & E5.5 & 104 & 0 & 0 & 0 \\
\hline \multirow[t]{3}{*}{ GR14 } & E3.5 & 120 & $9(7.5)$ & 35 & $36.7 \%$ \\
\hline & E4.5 & 104 & $11(10.6)$ & 42 & $51 \%$ \\
\hline & E5.5 & 104 & $4(3.8)$ & 19 & $22.1 \%$ \\
\hline \multirow[t]{3}{*}{ Total } & E3.5 & 330 & $15(4.5)^{\mathrm{a}}$ & 79 & $28.5 \%$ \\
\hline & E4.5 & 333 & $17(5.1)^{b}$ & 133 & $45 \%$ \\
\hline & E5.5 & 314 & $4(1.3)^{a^{\prime}, b^{\prime}}$ & 19 & $7.3 \%$ \\
\hline
\end{tabular}

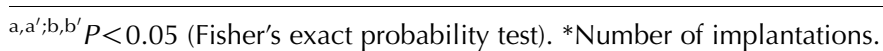

\section{Discussion}

In the present study, we examined the ability of in vitro aged blastocysts to generate ES mice. We found that E3.5 and E4.5 4n embryos were similarly efficient in producing ES mice; however, the efficiency was decreased in E5.5 4n embryos (Table 3). Our previous study showed that a larger cell number of host $4 \mathrm{n}$ embryos improves the birthrate of ES mice (Ohta et al. 2008). In this report, the cell number of host $4 n$ embryos was increased by aggregating multiple host $4 \mathrm{n}$ embryos at the two to four-cell stages, i.e., three two to four-cell stage $4 \mathrm{n}$ embryos were aggregated to generate one host $4 \mathrm{n}$ embryo. Although the E5.5 $4 \mathrm{n}$ embryos showed an increase in cell numbers (Table 2 ) similar to the previous study, the use of E5.5 4n embryos was ineffective in producing ES mice. These results suggest that not only
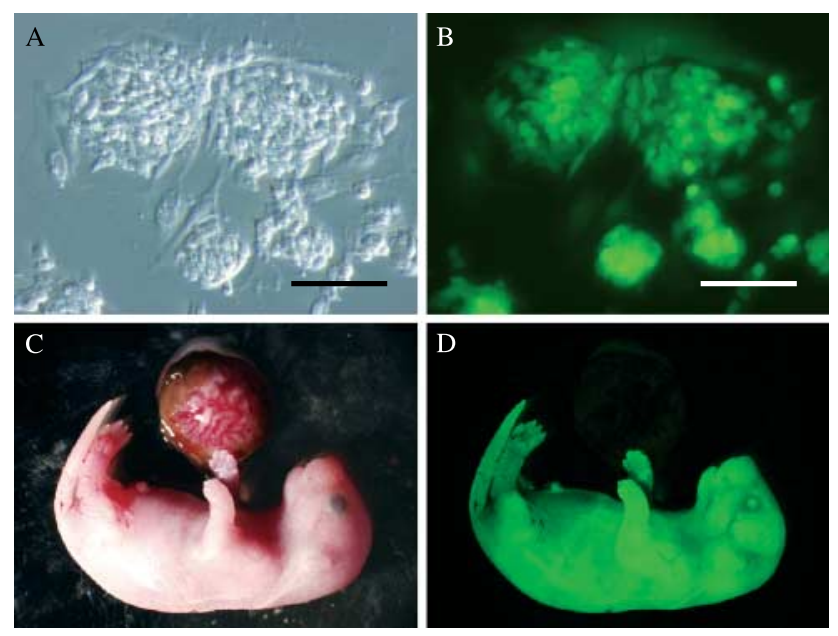

Figure 3 Generation of ES mice from E4.5 $4 \mathrm{n}$ blastocysts. The 129B6F1G1 ES cell line expressing GFP (A and B) was injected into the blastocoel of E4.5 $4 \mathrm{n}$ blastocysts. (C and D) ES mouse and placenta at $18.5 \mathrm{dpc}$ delivered from 129B6F1G1 $\leftrightarrow$ E4.5 4n embryos showing a light photograph $(\mathrm{C})$ and its fluorescence image (D). High-intensity green fluorescence was found in the progeny. Scale bars $=100 \mu \mathrm{m}$. the cell number but also the host embryonic stage is important for generating ES mice.

As stated above, the E5.5 $4 \mathrm{n}$ blastocysts were inefficient at producing ES mice, even though the cell numbers in the blastocysts were increased (Tables 2 and 3). Interestingly, the implantation and developmental abilities of the E5.5 $4 \mathrm{n}$ blastocysts were similar to those of the E3.5 4n or E4.5 $4 \mathrm{n}$ blastocysts (Table 5), which indicate that the low efficiency of E5.5 4 n blastocysts is not attributable to dysfunctions in implantation or subsequent development. To further this investigation, we carried out a cell tracing experiment to examine whether the ES cells injected into E5.5 4n blastocysts could contribute to the ICM. We found that the ES cells injected into E5.5 4n blastocysts made a relatively weak contribution to the ICM (Table 6 and Fig. 4A-B $\left.\mathrm{B}^{\prime \prime \prime}\right)$. These results suggest that the primary cause of inefficient production of ES mice from E5.5 blastocysts is inefficient homing of injected ES cells to the ICM, possibly due to the ICM status of the E5.5 $4 \mathrm{n}$ blastocysts. As the ICM of E5.5 4n blastocysts has already differentiated into two lineages (epiblast and primitive endoderm; Fig. 4C- $\mathrm{D}^{\prime \prime \prime}$ ), the formation of primitive endoderm may inhibit the integration of injected ES cells into the epiblast. Thus, although the cell numbers of the host $4 \mathrm{n}$ embryos are important to produce ES mice (Ohta et al. 2008), there is a time window for the integration of the ES cells into the host $4 \mathrm{n}$ epiblast. A potential strategy to increase the ES mouse producing ability of host $4 \mathrm{n}$ blastocysts is the addition of insulin to the culture medium, as it has been known to increase the cell numbers of $4 \mathrm{n}$ blastocysts (Koizumi \& Fukuta 1996).

Our results showed that E4.5 4n blastocysts were similarly efficient as those of E3.5 in generating ES mice (Table 3). The advantage in using E4.5 blastocysts is that they can be injected at a more convenient time than E3.5 blastocysts. As shown in Fig. 1 and Table 1, almost all E4.5 4n blastocysts formed a blastocoel, whereas morula-stage embryos were still present in E3.5 4n 
Table 4 Characterization of newborn embryonic stem cell (ES) mice generated from $4 \mathrm{n}$ blastocysts of different developmental ages.

\begin{tabular}{|c|c|c|c|c|c|c|c|}
\hline \multirow[b]{2}{*}{ Type of host } & \multirow[b]{2}{*}{$\mathbf{B W}(n)^{+}$} & \multirow[b]{2}{*}{$\mathbf{P W}(n)^{\dagger}$} & \multicolumn{4}{|c|}{ Number of abnormal pups* } & \multirow[b]{2}{*}{$\%$ Abnormal pups } \\
\hline & & & $\mathrm{AH}$ & LO & OELO & OEAH & \\
\hline E3.5 & $1.60 \pm 0.44(17)$ & $0.27 \pm 0.08(17)$ & 1 & 2 & - & - & $17.6 \%$ \\
\hline E4.5 & $1.55 \pm 0.22(24)$ & $0.24 \pm 0.05(24)$ & - & 1 & - & 2 & $12.5 \%$ \\
\hline E5.5 & $1.88 \pm 0.6(4)$ & $0.24 \pm 0.06$ & - & 1 & 1 & - & $50 \%$ \\
\hline
\end{tabular}

BW, body weight; PW, placenta weight. *OE, open eyelids; AH, abdominal hernia; LO, large offspring; OELO, pup showing both open eyelids and large offspring; OEAH, pup showing both open eyelids and abdominal hernia. ${ }^{\dagger}$ Values are expressed as mean \pm s.D. (g).

embryos. Although some of the ES mice derived from E4.5 4n embryos showed abnormalities such as abdominal hernia or large offspring syndrome (Table 4), the frequency of these defects was similar to that in ES mice generated from E3.5 4n embryos (Table 4), indicating that ES mice can be produced from both E4.5 and E3.5 $4 \mathrm{n}$ embryos. Thus, our results demonstrate that the use of E4.5 embryos is effective in generating ES mice.

In general, ES mice can be produced using two methods (Nagy et al. 2003): injection of ES cells into 4n blastocysts (Wang et al. 1997) or aggregation of ES cells with 4n four-cell stage embryos (Nagy et al. 1990, 1993). In our previous study, we demonstrated that the use of multiple $4 n$ host aggregates (e.g., three $4 n$ embryos) is more effective in generating ES mice than the use of one or two 4n host embryos (Ohta et al. 2008). In this report, the birthrate of ES mice using E14 and 129B6F1G1 strains with three $4 \mathrm{n}$ embryos was 14.3 and $9.3 \%$ respectively (Ohta et al. 2008). As this birthrate was calculated based on the number of transferred $\mathrm{ES} \leftrightarrow 3 \times 4 \mathrm{n}$ embryos, that estimated from the number of embryos used was $4.8 \%$ for E14 and $3.1 \%$ for 129B6F1G1. In the present study, the birthrate of ES mice via blastocyst injection using E3.5 and E4.5 embryos was $\sim 3.8 \%$ for $\mathrm{E} 14$ and $1.8 \%$ for 129B6F1G1 (Table 3). Thus, the production of ES mice based on the number of embryos employed using blastocyst injection is similar to that using multiple $4 \mathrm{n}$ embryos. These two techniques can be selectively used depending on the research purpose; for example, blastocyst injection is effective for assessing donor cell function since micromanipulation allows the selection of donor cells. On the other hand, the use of $3 \times 4 \mathrm{n}$

Table 5 Implantation and developmental abilities of $4 \mathrm{n}$ blastocysts.

\begin{tabular}{lcll}
\hline Type of embryo & $\begin{array}{c}\text { Number of } \\
\text { embryos } \\
\text { transferred }\end{array}$ & $\begin{array}{c}\text { Number of } \\
\text { implantations } \\
(\%)^{*}\end{array}$ & $\begin{array}{c}\text { Number of } \\
\text { embryos } \\
\text { recovered }(\%)^{*}\end{array}$ \\
\hline E3.5 & 83 & $46(55.4)$ & $5(6.0)$ \\
E4.5 & 74 & $26(35.1)$ & $3(4.1)$ \\
E5.5 & 116 & $63(54.3)$ & $10(8.6)$ \\
\hline
\end{tabular}

The $4 \mathrm{n}$ blastocysts of different developmental ages were transferred into pseudopregnant females and assessed at E7.5. No significant difference was found ( $P>0.05$; Fisher's exact probability test).

*Percentages relative to the number of embryos transferred were shown in parentheses. embryos is effective in producing ES mice because the procedure is easier to perform. Recently, another procedure for producing ES mice have been reported, in which ES cells were injected into $2 \mathrm{n}$ host four- to eight-cell stage embryos (Poueymirou et al. 2007). Although we could not compare the efficiencies of this and the above-described procedures, this method may also be suitable for the production of ES mice.

\section{Materials and Methods}

\section{Mice}

ICR mice were purchased from SLC (Hamamatsu, Japan). All animal experiments conformed to the Guide for the Care and Use of Laboratory Animals and were approved by the Institutional Committee of the Laboratory Animal Experimentation of the RIKEN Kobe Institute.

\section{ES cell lines}

The ES cell line E14 (Hooper et al. 1987) was derived from the inbred mouse strain 129/Ola in 1985 by Dr Martin Hooper in Edinburgh, Scotland, and obtained through Dr Peter Mombaerts (Rockefeller University). 129B6F1G1 and GR14 are nuclear transfer-derived ES (ntES) cell lines (Wakayama et al. 2001) previously established in our laboratory using Sertoli cells from a 129B6F1 background with GFP (Ohta \& Wakayama 2005) and tail tip cells of a male mouse (129BDF2; Wakayama et al. 2005) respectively, as donors for nuclear transfer. Karyotype analysis revealed that the ES cell lines used had the normal karyotype at the following percentages (number of metaphases with normal karyotype in parentheses): $46 \%$ (12/26) for E14; 35\% (9/26) for 129B6F1G1; and $54 \%(14 / 26)$ for GR14.

Table 6 Homing efficiencies of embryonic stem (ES) cells for the inner cell mass (ICM) of host $4 \mathrm{n}$ blastocysts.

\begin{tabular}{lccc}
\hline Type of embryo & $\begin{array}{c}\text { Number of } \\
\text { embryos } \\
\text { examined }\end{array}$ & $\begin{array}{c}\text { Number of } \\
\text { embryos with } \\
\text { GFP positive ES } \\
\text { cells }(\%)\end{array}$ & $\begin{array}{c}\text { Number of } \\
\text { embryos with } \\
\text { ES cell contri- } \\
\text { bution to the } \\
\text { ICM }(\%)\end{array}$ \\
\hline E3.5 & 58 & $48(82.8)$ & $41(85.4)^{\mathrm{a}}$ \\
E4.5 & 44 & $37(84.1)$ & $25(67.6)$ \\
E5.5 & 52 & $43(82.7)$ & $13(30.2)^{\mathrm{a}^{\prime}}$ \\
\hline
\end{tabular}

${ }^{\mathrm{a}, \mathrm{a}^{\prime}} \mathrm{P}<0.05$ (Fisher's exact probability test). 

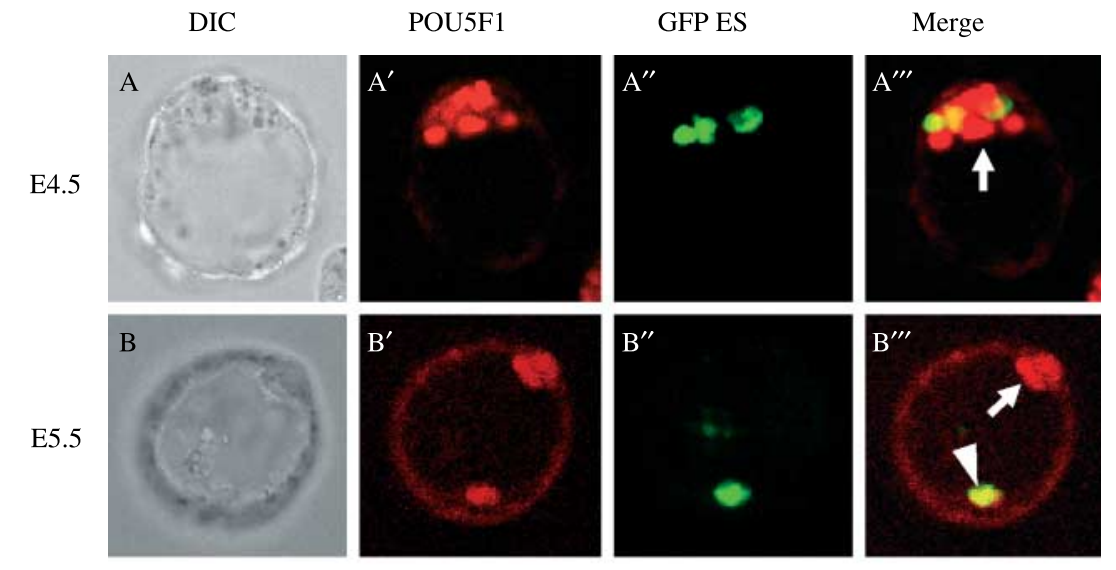

DIC
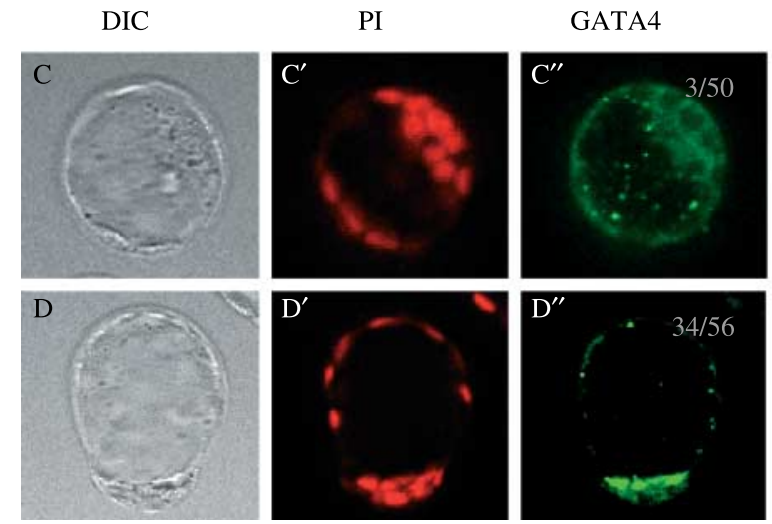

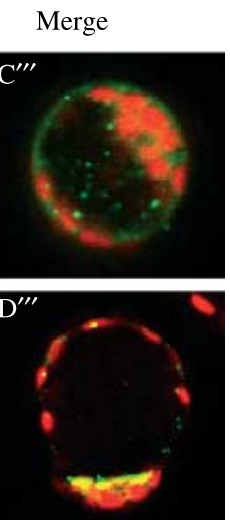

Figure 4 Fate of ES cells injected into E4.5 or E5.5 4n blastocysts. ES cells that express GFP (129B6F1 ES cell line) were injected into E4.5 (A- $\left.\mathrm{A}^{\prime \prime \prime}\right)$ or E5.5 (B-B $\left.{ }^{\prime \prime \prime}\right) 4 \mathrm{n}$ blastocysts. At $24 \mathrm{~h}$ after ES cell injection, the blastocysts were stained with anti-POU5F1 antibody that was visualized with red fluorescence. (A and B) DIC images of E4.5 and E5.5 blastocysts. POU5F1 expression $\left(A^{\prime}\right.$ and $\left.B^{\prime}\right)$ and injected ES cells $\left(A^{\prime \prime}\right.$ and $\left.B^{\prime \prime}\right)$ are shown. $\left(A^{\prime \prime \prime}\right.$ and $\left.B^{\prime \prime \prime}\right)$ Merged images of $A^{\prime}$ and $A^{\prime \prime}, B^{\prime}$ and $B^{\prime \prime}$. Arrows indicate endogenous ICM. In B'I', ES cells are indicated as an arrowhead. $\left(\mathrm{C}-\mathrm{D}^{\prime \prime \prime}\right)$ Primitive endoderm formation by $\mathrm{E} 4.5$ and E5.5 $4 \mathrm{n}$ blastocysts. (C and D) DIC images of E4.5 and E5.5 $4 \mathrm{n}$ blastocysts. $\mathrm{PI}\left(\mathrm{C}^{\prime}\right.$ and $\left.\mathrm{D}^{\prime}\right)$ and GATA4 expression $\left(\mathrm{C}^{\prime \prime}\right.$ and $\left.\mathrm{D}^{\prime \prime}\right)$ are shown. In $\mathrm{C}^{\prime \prime}$ and $\mathrm{D}^{\prime \prime}$, numbers of GATA4 positive $4 \mathrm{n}$ blastocysts are shown. ( $C^{\prime \prime \prime}$ and $\left.D^{\prime \prime \prime}\right)$ Merged images of $C^{\prime}$ and $\mathrm{C}^{\prime \prime}, \mathrm{D}^{\prime}$ and $\mathrm{D}^{\prime \prime}$.

\section{ES cell culture conditions}

ES cells were grown in KNOCKOUT Dulbecco's modified Eagle's medium (Invitrogen) supplemented with 20\% heatinactivated fetal bovine serum (FBS; Sigma-Aldrich), 1000 units of leukemia inhibitory factor/ml (Invitrogen), and the following reagents: 1\% penicillin-streptomycin (Invitrogen); 1\% L-glutamine (Specialty Media, Phillipsburg, NJ, USA); 1\% non-essential amino acids (Specialty Media); $1 \%$ nucleosides (Specialty Media); and $1 \% \quad \beta$-mercaptoethanol (Specialty Media). Cells were cultured in a gelatin-coated dish in feeder-free conditions and split 1:5 or 1:10 every $48 \mathrm{~h}$.

\section{Generation of $E S \leftrightarrow 4 n$ embryos}

Blastocysts with an ICR background were used as hosts for $4 \mathrm{n}$ embryos. Briefly, superovulated ICR females were mated with ICR males, and two-cell stage embryos were collected from the oviducts at $1.5 \mathrm{dpc}$. To generate $4 \mathrm{n}$ embryos, two-cell stage embryos were electrofused using an electro cell fusion system (Model LF101; Nepagene, Chiba, Japan). Fused embryos were selected and cultured in CZB medium (Chatot et al. 1989). Each ES cell line was used within three passages in our experiments. Approximately, $15 \mathrm{ES}$ cells were injected into the blastocysts using a piezo-actuating micromanipulator, using essentially the same procedure as that reported by Wang et al. (1997). All blastocysts injected with ES cells were transferred to pseudopregnant ICR females at $2.5 \mathrm{dpc}$ (10-16 chimeric embryos/ mouse), which were analyzed at $18.5 \mathrm{dpc}$. Body and placenta weight were assessed in newborn ES mice. ES mice with open eyelids, abdominal hernia, or large offspring (body weight more than $2.0 \mathrm{~g}$ ) were categorized as abnormal pups.

\section{Assessment of cell numbers of blastocysts}

The total and TE cell numbers of blastocysts were determined. Propidium iodide (PI) staining and immunostaining for CDX2 were used to indicate the total and TE cell numbers respectively. The cell number for ICM was roughly estimated as the TE cell number subtracted from total cell number (total TE). Blastocysts were fixed with $4 \%$ paraformaldehyde, washed with PBS containing 1\% BSA, and incubated with anti-CDX2 MAB (1:200; BioGenex, San Ramon, CA, USA). The primary antibody was visualized with goat anti-mouse IgG conjugated with Alexa Fluor 488 (Molecular Probes, Eugene, OR, USA). After immunostaining for CDX2, blastocysts were incubated in PBS containing $1 \mu \mathrm{g} / \mathrm{ml} \mathrm{PI}$. Serial confocal images were taken using fluorescence confocal microscopy (Yamagata et al. 2005), and three-dimensional images of blastocysts were reconstructed using MetaMorph software (Universal Imaging Co., Downingtown, PA, USA). More than ten blastocysts were stained and the total (PI-positive) and TE (CDX2-positive) cell numbers were determined. Immunostaining for POU5F1 or GATA4 was performed employing the same procedure for the CDX2 staining using an anti-POU5F1 MAB (C-10; 1:200; Santa 
Cruz Biotechnology Inc., CA, USA; catalog no. sc-5279) or anti-GATA4 polyclonal antibody (1:200; Santa Cruz Biotechnology, Santa Cruz, CA, USA; catalog no. sc-9053).

\section{Statistical analysis}

The Fisher's exact probability test (Tables 3, 5, and 6) and Student's $t$-test (Table 2) were performed. $P<0.05$ was considered statistically significant.

\section{Declaration of interest}

The authors declare that there is no conflict of interest that would prejudice the impartiality of this scientific work.

\section{Funding}

This work was supported by grants for Scientific Research in Priority Areas (15080221) and the Project for the Realization of Regenerative Medicine (research field: technical development of stem cell manipulation) to T W by the Ministry of Education, Culture, Sports, Science, and Technology of Japan.

\section{Acknowledgements}

We thank Dr Kazuo Yamagata for assistance with confocal microscopy. We also thank the Laboratory for Animal Resources and Genetic Engineering for housing the mice used in the study.

\section{References}

Chatot CL, Ziomek CA, Bavister BD, Lewis JL \& Torres I 1989 An improved culture medium supports development of random-bred 1-cell mouse embryos in vitro. Journal of Reproduction and Fertility 86 679-688.

Eakin GS \& Behringer RR 2003 Tetraploid development in the mouse. Developmental Dynamics 228 751-766.

Eakin GS, Hadjantonakis A-K, Papaioannou VE \& Behringer RR 2005 Developmental potential and behavior of tetraploid cells in the mouse embryo. Developmental Biology 288 150-159.

Hooper M, Hardy K, Handyside A, Hunter S \& Monk M 1987 HPRTdeficient (Lesch-Nyhan) mouse embryos derived from germline colonization by cultured cells. Nature 326 292-295.
Kaufman MH \& Webb S 1990 Postimplantation development of tetraploid mouse embryos produced by electrofusion. Development 110 1121-1132.

Koizumi N \& Fukuta K 1996 Effect of insulin on in vitro development of tetraploid mouse embryos. Experimental Animals 45 179-181.

Kunath T, Arnaud D, Uy GD, Okamoto I, Chureau C, Yamanaka Y, Heard E, Gardner RL, Avner P \& Rossant J 2005 Imprinted X-inactivation in extraembryonic endoderm cell lines from mouse blastocysts. Development 132 1649-1661.

Liu L, Czerwiec E \& Keefe DL 2004 Effect of ploidy and parental genome composition on expression of Oct-4 protein in mouse embryos. Gene Expression Patterns 4 433-441.

Nagy A, Gócza E, Diaz EM, Prideaux VR, Iványi E, Markkula M \& Rossant J 1990 Embryonic stem cells alone are able to support fetal development in the mouse. Development 110 815-821.

Nagy A, Rossant J, Nagy R, Abramow-Newerly W \& Roder JC 1993 Derivation of completely cell culture-derived mice from early-passage embryonic stem cells. PNAS $908424-8428$.

Nagy A, Gertsenstein M, Vinterstein K \& Behringer RR 2003 Production of chimeras. In Manipulating the Mouse Embryo: A Laboratory Manual, 3 edn, pp 453-506. Eds A Nagy, M Gertsenstein, K Vintersten \& R Behringer. New York: Cold Spring Harbor Laboratory Press.

Ohta H \& Wakayama T 2005 Generation of normal progeny by intracytoplasmic sperm injection following grafting of testicular tissue from cloned mice that died postnatally. Biology of Reproduction 73 390-395.

Ohta H, Sakaide Y, Yamagata K \& Wakayama T 2008 Increasing the cell number of host tetraploid embryos can improve the production of mice derived from embryonic stem cells. Biology of Reproduction 79 486-492.

Poueymirou WT, Auerbach W, Frendewey D, Hickey JF, Escaravage JM, Esau L, Doré AT, Stevens S, Adams NC, Dominguez MG et al. 2007 F0 generation mice fully derived from gene-targeted embryonic stem cells allowing immediate phenotypic analyses. Nature Biotechnology 25 91-99.

Wakayama T, Tabar V, Rodriguez I, Perry AC, Studer L \& Mombaerts P 2001 Differentiation of embryonic stem cell lines generated from adult somatic cells by nuclear transfer. Science 292 740-743.

Wakayama S, Ohta H, Kishigami S, Thuan NV, Hikichi T, Mizutani E, Miyake M \& Wakayama T 2005 Establishment of male and female nuclear transfer embryonic stem cell lines from different mouse strains and tissues. Biology of Reproduction 72 932-936.

Wang ZQ, Kiefer F, Urbánek P \& Wagner EF 1997 Generation of completely embryonic stem cell-derived mutant mice using tetraploid blastocyst injection. Mechanisms of Development 62 137-145.

Yamagata K, Yamazaki T, Yamashita M, Hara Y, Ogonuki N \& Ogura A 2005 Noninvasive visualization of molecular events in the mammalian zygote. Genesis 43 71-79.

Received 30 April 2008

First decision 28 May 2008

Revised manuscript received 15 July 2008

Accepted 28 August 2008 